\title{
A Geometrical Model for Surface Roughness Prediction When Face Milling Al 7075-T7351 with Square Insert Tools
}

\author{
Patricia Muñoz-Escalona ${ }^{a}$, Paul G Maropoulos ${ }^{\text {b }}$ \\ ${ }^{a}$ University of Strathclyde, Department of Mechanical and Aerospace Engineering. Glasgow, UK \\ ${ }^{\mathrm{b}}$ University of Bath, Department of Mechanical Engineering, Bath, UK
}

\begin{abstract}
Surface quality is important in engineering and a vital aspect of it is surface roughness, since it plays an important role in wear resistance, ductility, tensile, and fatigue strength for machined parts. This paper reports on a research study on the development of a geometrical model for surface roughness prediction when face milling with square inserts. The model is based on a geometrical analysis of the recreation of the tool trail left on the machined surface. The model has been validated with experimental data obtained for high speed milling of aluminium alloy (Al 7075-T7351) when using a wide range of cutting speed, feed per tooth, axial depth of cut and different values of tool nose radius $(0.8 \mathrm{~mm}$ and $2.5 \mathrm{~mm})$, using the Taguchi method as the Design of Experiments. The experimental roughness was obtained by measuring the surface roughness of the milled surfaces with a non-contact profilometer. The developed model can be used for any combination of material workpiece and tool, when tool flank wear is not considered and is suitable for using any tool diameter with any number of teeth and tool nose radius. The results show that the developed model achieved an excellent performance with almost $98 \%$ accuracy in terms of predicting the surface roughness when compared to the experimental data.
\end{abstract}

Keywords: Face milling, surface roughness, Taguchi, tool run outs.

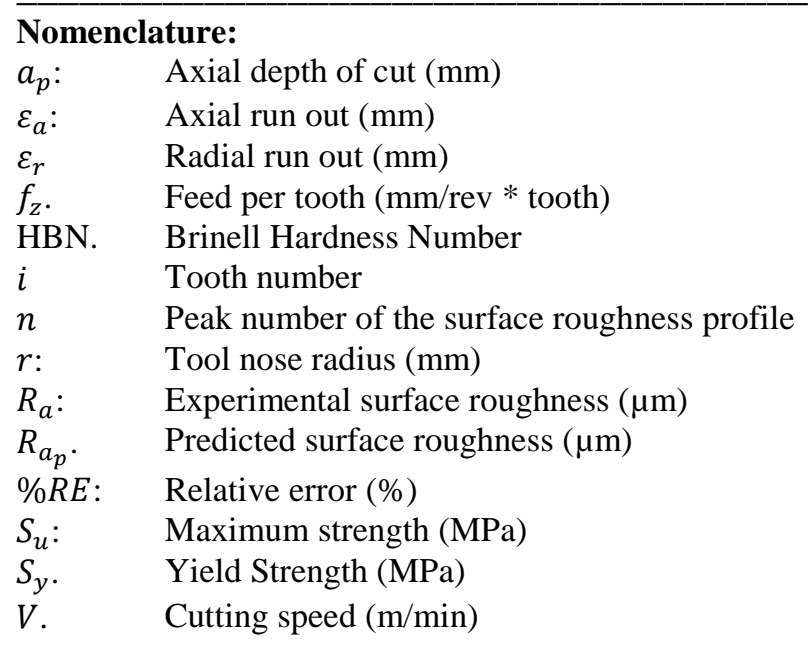




\section{Introduction}

Product quality has always been one of the most important elements in manufacturing operations. In view of the present global economy and competition, continuous improvement in quality has become a major priority, particularly for major corporations in industrialized countries, such as USA, UK, Germany, Japan, etc. The range of technologies involved in the manufacturing sector continues to grow with the introduction of improved equipment and tools in order to produce high quality final products, with specific characteristics, such as: dimensional accuracy, surface roughness, etc. Machining processes require specific attention to guarantee the quality of a final product against certain manufacturing specifications. Besides the obvious problems related to correct dimensions, one of the biggest problems is achieving the appropriate finish or surface smoothness on the workpiece. Surfaces are commercially and technologically important for a number of reasons. Few reasons are: 1) esthetic; a smooth and free of scratches surface is more likely to give a favorable impression to costumer, 2) surfaces affect safety, 3) surfaces interact with its environment, due to its influence on mechanical properties such as: wear, corrosion and lubrication [1] Kim, 1997, [2] Medicus, 2001, [3] Gadelmawla, 2002, [4] Saï, 2005, [5] Cemal, 2009.

General defects caused by and produced during component manufacturing can be responsible for inadequate surface integrity. These defects are usually caused by a combination of factors, such as defects in the original material, the method by which the surface is produced, and lack or proper control of process parameters that can result in excessive stresses and temperature. For example, roughness is a measure of the texture of a surface and is a consequence of the cutting parameters, tool geometry, etc. used during the machining process. Depending on how rough the surface is (deepness of the grooves left by the tool on the machined surface) a piece can wear more quickly and have higher friction coefficients than a smoother surface [6] (Childs, 2000).

One of the most promising advanced manufacturing technologies in the last decade is the high speed cutting, due to its potential for faster production rates, shorter lead times, reduced costs and improved part quality, since the technique combines high spindle speeds with increased feed rates [7] (Kalpakjian, 2003). This results in a high chip-forming rate and lower milling forces, producing an improved surface quality and tighter tolerances. However, appropriate tools and cutting parameters should be used in order to complete the machining process without damaging the cutting tool. This is the main factor of why the prediction and control of the surface roughness and the tool wear are challenges to researchers.

In recent years there have been several proposals regarding different models for surface roughness predictions during a milling process. 
Baek, et al. [8] analyzed the effects of the insert run out errors and the variation of the feed rate on the surface roughness operations using a surface roughness model. The experiments were conducted in AISI 1041 ductile steel.

In 2004, Wang [9] analyzed the influence of cutting conditions and tool geometry on the surface roughness when slot end milling aluminum alloy 2014-T6. The developed surface roughness models for both dry cutting and coolant conditions were built using a Response Surface Methodology (RSM). The results showed that the dry-cut roughness was reduced by applying cutting fluid.

The research made by Franco, et al. [10], contributes on the development of a numerical model for surface roughness profile prediction when using round inserts. The model relates the feed, the cutting tool geometry and the tool errors, incorporating an algorithm that makes possible the variation of the surface roughness from the values that can be adopted by the tool errors.

Researcher, Oktema et al. [11], predicted the surface roughness by using RSM (Response Surface Methodology) coupled with GA (Genetic Algorithms). The studies were made in Al 7075-T6.

In 2005, Reddy, et al. [12] studied the effect of tool geometry (radial rake angle and tool nose radius) and cutting conditions (cutting speed and feed rate) on the machining performance during end milling of medium carbon steel. First and second order mathematical models, in terms of machining parameters were developed for surface roughness prediction using RSM. The results showed that the cutting speed, the feed, the radial rake angle and the tool nose radius are the primary factors influencing the surface roughness of medium carbon steel during end milling processes.

The study of plane surface generation mechanism in flat end milling process was made by Ryua, et al. [13]. They concluded that the bottom of a flat end milling has an end cutting edge angle that plays an important role in surface texture and that the surface texture is produced by superposition of conical surfaces generated by the end cutting edge rotation. The evaluation of the generated surface texture characteristic was done using RSM.

Also Ozcelik [14] in 2006, presented the development of a statistical model for surface roughness estimation in a high-speed flat end milling process, under wet cutting conditions, using machining variables such as spindle speed, feed rate, depth of cut and step over.

Researcher, Jesuthanam, et al. [15], proposed the development of a novel hybrid Neural Network (NN) trained with Genetic Algorithm (GA) and Particle Swarm Optimization (PSO) for the prediction of surface roughness. The proposed hybrid NN was found to be competent in terms of computational speed and 
efficiency over the NN model. In 2007, Zhang et al. [16] studied the Taguchi design application to optimize the surface quality of a face milling operation when using a CNC. The results verified that the Taguchi design was successfully in optimizing the milling parameters for surface roughness.

Bharathi S and Baskar N in 2012 [17] developed a generalized model based on Particle Swarm Optimization (PSO) technique to achieve a desired surface roughness when face milling aluminium. The machining time was included as input parameter together with cutting speed, feed and depth of cut. They concluded that the use of optimization technique replaces the selection of cutting parameters by trial and error method

Finally, Arrazola P.J. et al in 2013 [18] compiled different advances in the modeling of machining processes. In its paper the advances in predictive, analytical, computational and empirical models among others for the prediction of variables such as surface roughness, cutting forces, stresses, chip formation etc. are highlighted.

From analyzing all the literature, it has been observed that the proposed models are based on computational, numerical analysis and complex mathematical calculus and basically addresses the use of end milling processes for round inserts when using a face milling process with a specific number of teeth and tool diameter. Based on these findings, the aim of this research is to develop a model for surface roughness prediction based solely on geometry when face milling with square inserts. The model can be used for any tool geometry regarding tool nose radius, tool diameter and number of teeth, where also parameters such as the feed per tooth and tool run outs are considered. The validation of the model will be conducted by using experimental surface roughness data obtained when face milling aluminium alloy 7075-T7351 under specific cutting conditions.

This new contribution will represent a useful capability for researchers in the area since it will allow the prediction of roughness before conducting trial and error experiments, representing saving in cost and time.

\section{Development of the geometrical model for surface roughness prediction}

The proposed geometrical model is developed based on a geometrical analysis. In this case, a visual observation of the Al 7075-T7351 machined surface is conducted and a recreation of the tool trail left on the machined surface is analyzed. In this case the tool trail is developed considering the feed per tooth, the cutting tool nose radius and the tool run out errors. From previous research $[8,10]$ it was noted the influence of the tool run out variable on the surface roughness and the importance of including this variable for the prediction of the surface roughness.

The tool run outs (axial $\left(\varepsilon_{a}\right)$ and radial $\left(\varepsilon_{r}\right)$ deviations of the tool) are defects that consist in small discrepancies in the relative position of the different cutting teeth. These discrepancies are obtained for many reasons such as: manufacturing tolerances of the cutting tool inserts and seats, inaccuracy in the fixture of the indexable inserts, uncertainty in the clamping force of the insert screws, imperfections in the machine tool axis movement, etc. [10] 
Figure 1 shows a schematic of the tool run outs and angle $K_{i}$ and Figure 2 shows the contribution of the tool run outs on the surface roughness profile.

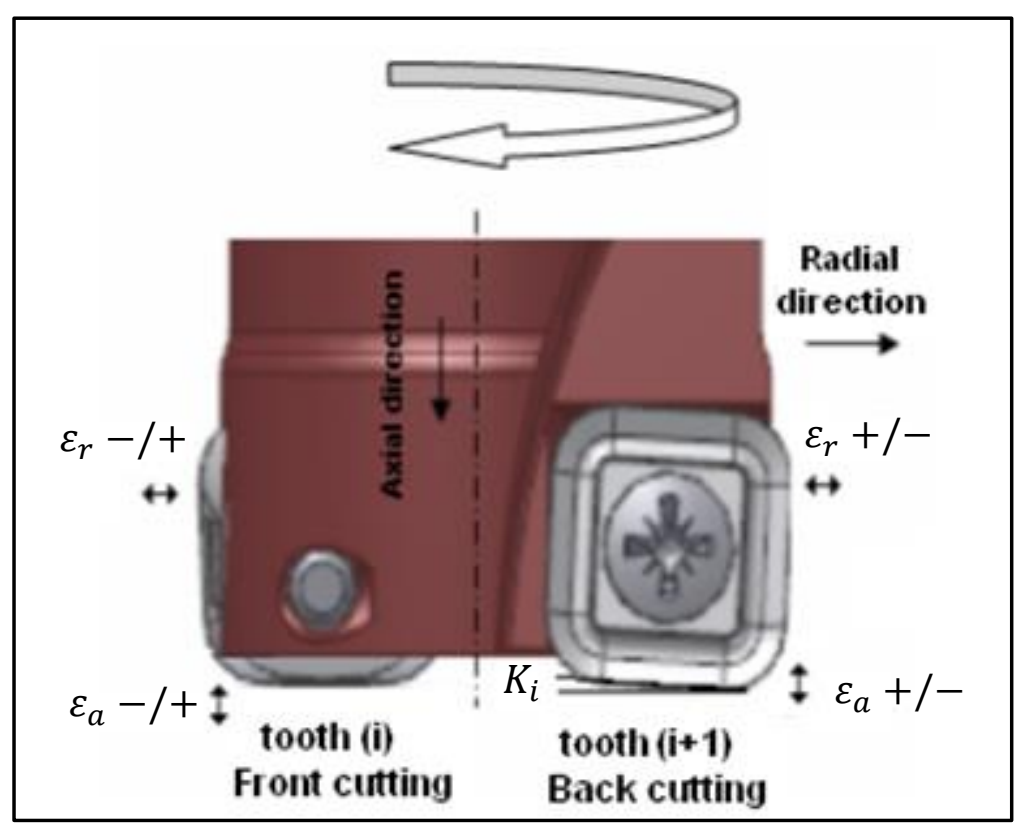

Figure 1- Schematic of the axial $\left(\varepsilon_{a}\right)$ and radial $\left(\varepsilon_{r}\right)$ deviation during rotation of the tool and angle, $K_{i}$.

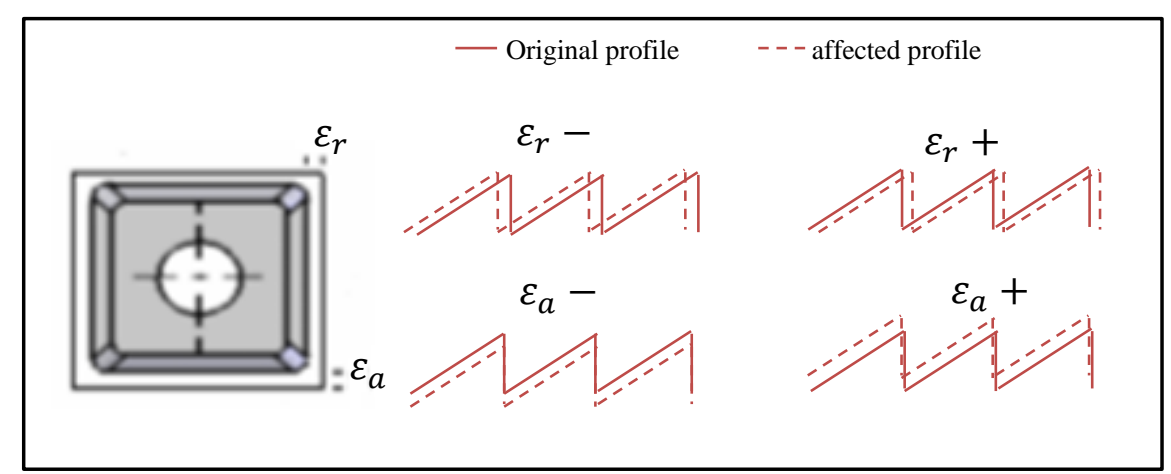

Figure 2- Illustration of how the 2D surface roughness profile is affected when considering "+" or "-_" tool run outs. 
When analyzing Figure 2, it is observed that the axial tool deviation is the tool deviation that produces displacement of the surface roughness profile in an "up or down" direction (depending on the sign of the deviation), affecting the deepness of the profile and consequently the value of surface roughness. The radial tool deviation produces a small movement of the profile in a "right or left" direction (depending on the sign of the deviation) and it does not affect the height of the profile.

In the geometrical model a two teeth cutting tool is considered, tooth (i) is considered the pattern with $\left(\varepsilon_{a}=\varepsilon_{r}=0\right)$ and tooth (i+1) will have $\left(\varepsilon_{a} \neq \varepsilon_{r} \neq 0\right)$

In order to simplify the model the back cutting process will not be considered. Also despite the influence of tool wear on surface roughness this variable is not included in the model since: 1) new inserts are employed during each trial, 2) the length of cut used for the milling process is small $(333.3 \mathrm{~mm}), 3)$ the milling process was conducted under MQL (Minimum Quantity Lubrication), 4) the inclusion of tool wear would require a much longer time for experiments and a higher budget, considering it a completely separate study, outside the scope of this research.

Figure 3 show a scheme of the trail left by the cutting tool on the machined surface, where the roughness profile is observed. In this case tooth (i) is represented by thick continues line and tooth (i+1) is represented by thick dash line.

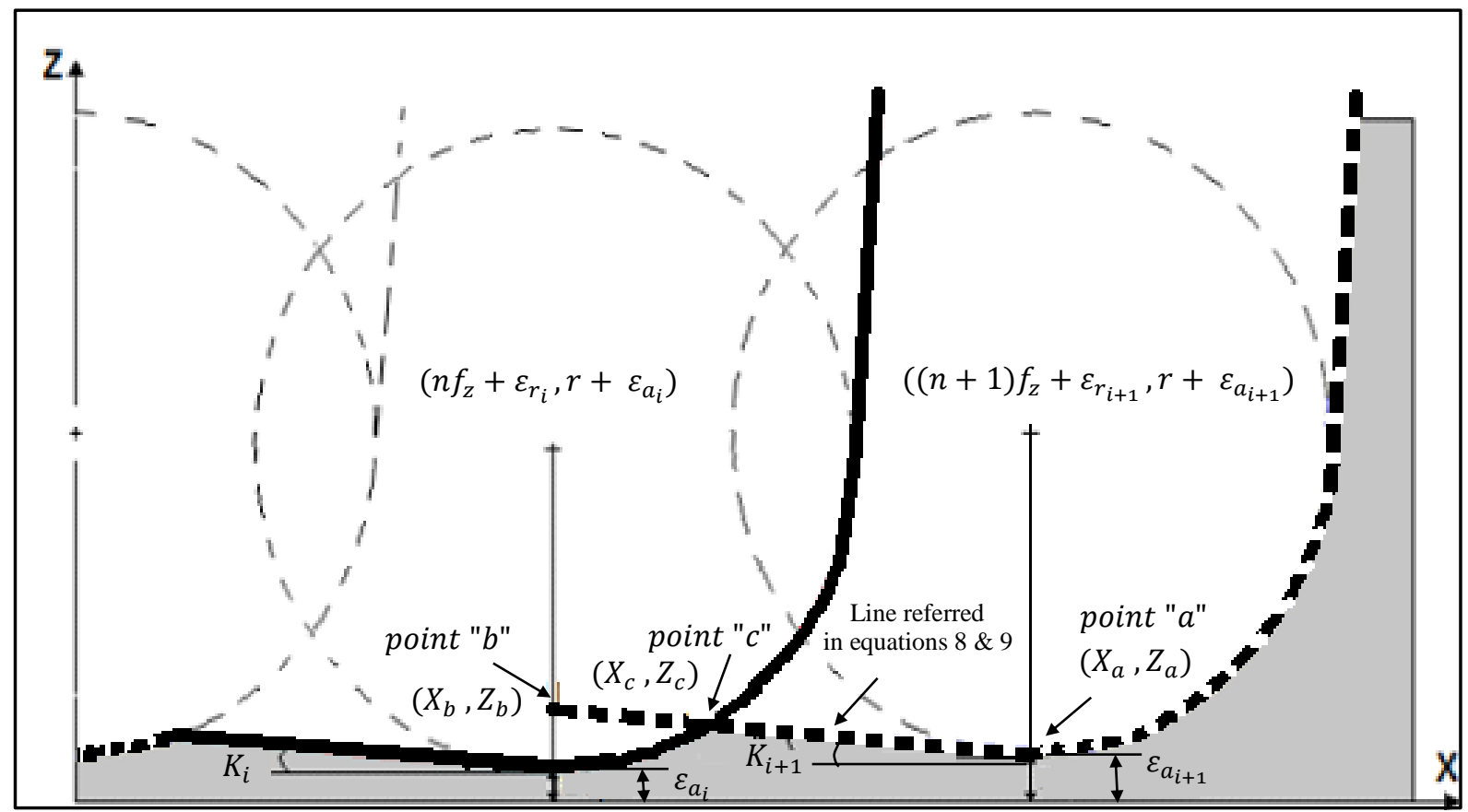

Figure 3- Scheme of the trail left by the cutting tool where the roughness profile can be observed 
When analyzing this figure 3, which is the starting point for the development of the model, it is observed that as the tool moves along the cutting length, tooth (i) starts to cut (thick continues line) and then tooth (i+1) (thick dash line) which is $f_{Z}$ away from tooth (i) starts to cut as well. As observed, since the inserts selected for the cutting process have a square geometry, they are composed of two sections. The first section is delimited by a circle section (tool's nose radius) and the second section is delimited by a line (giving shape to a square with round corners).

By taking into account the intersection of the section of the circle (negative size, $\cup$ ) and the section of the line, and by also considering the variables $f_{z}$ (feed per tooth) and $r$ (tool nose radius) which are also involved in the trail left by the tool on the machined surface, the intersection point "c", whose coordinates are $\left(X_{c}, Z_{c}\right)$ is obtained. The height of this point "c" corresponds to $Z_{c}$, which also corresponds to the surface roughness value (predicted by the model). This point "c" (intersection between the circle (tool's nose radius from tooth (i) and the line of the tool's shape from tooth $(i+1)$ ) is repeated along the machined surface, defining the surface roughness profile (shaded area in figure 3). It must be highlighted that this height $\left(Z_{c}\right)$,changes depending on the axial tool run outs deviations that are considered for each of the tool's teeth.

Also this figure 3 shows the parameters that are used to determine the surface profile. As it is observed the figure includes the position of tooth (i) and tooth (i+1), as well as the marks left by the teeth, denoted as " $n$ " and " $n+1$ ". It must be highlighted that these marks depends on the position of the teeth.

Equation 1 presents the negative part of the square root of the circle equation, which in this case is the part of the circle that it is considered for the development of the model $(\cup)$.

$$
Z=Z_{n}-\sqrt{r^{2}-\left(X-X_{n}\right)^{2}}
$$

Where $X_{n}$ and $Z_{n}$ values are the coordinates of the center of the circle (that forms the tool's nose radius).

For mark " $n$ " these coordinates are:

$$
\begin{gathered}
X_{n}=n f_{z}+\varepsilon_{r_{i}} \\
Z_{n}=r+\varepsilon_{a_{i}}
\end{gathered}
$$

For mark " $n+1$ " these coordinates are:

$$
\begin{gathered}
X_{n+1}=(n+1) f_{z}+\varepsilon_{r_{i+1}} \\
Z_{n+1}=r+\varepsilon_{a_{i+1}}
\end{gathered}
$$


When analyzing Figure 3 it is observed that the points that need to be considered for the roughness profile are point "a" and point "c", as these points will appear along the roughness profile during the cutting process.

Point "a" coordinates are:

$$
\begin{gathered}
X_{a}=(n+1) f_{z}+\varepsilon_{r_{i+1}} \\
Z_{a}=\varepsilon_{a_{i+1}}
\end{gathered}
$$

As previously mentioned point "c" defines the height of the profile and as observed when analyzing Figure 3 this point is obtained through the intersection of the circle section that corresponds to tool's nose radius of tooth (i) ) and the linear section of tooth (i+1). These coordinates are named $X_{c}$ and $Z_{c}$. The intersection point is obtained by equating the equation of a circle (equation 1) and the equation of a line which is reported in equation 8 .

$$
Z_{L}=m X_{L}+b
$$

Where:

$Z_{L}$ : Coordinate $\mathrm{Z}$ at any point of the line with a $X_{L}$ coordinate

$X_{L}$ : Coordinate $\mathrm{X}$ at any point of the line with a $Z_{L}$ coordinate

$m:$ Slope

$b$ : Interception with $\mathrm{Z}$ axis. In this case the interception will give $\mathrm{Z}$ coordinate of point $\mathrm{b}$, named $Z_{b}$

Equation 9 reports the equation of the slop

$$
m=-\tan \left(K_{i+1}\right)
$$

When substituting equation 9 in equation 8 and considering $X_{L}=X_{a}$ and $Z_{L}=Z_{a}$ then the cutting point "b" with the $\mathrm{Z}$ axis is obtained and shown in equation 10 where as previously mentioned $b=Z_{b}$.

$$
\left.Z_{b}=\left[(n+1) f_{z}+\varepsilon_{r_{i+1}}\right)\right] \cdot \tan \left(K_{i+1}\right)+\varepsilon_{a_{i+1}}
$$

When substituting equation 10 and 9 in equation 8 the following is obtained. 


$$
Z_{L}=-\tan \left(K_{i+1}\right) \cdot\left[X-\left((n+1) f_{z}+\varepsilon_{r_{i+1}}\right)\right]+\varepsilon_{a_{i+1}}
$$

In order to obtain $X_{c}$ coordinate, which is the intersection between the section of the circle (tool's nose radius) and the section of the line, equation 1 is equated with equation 8, obtaining equation 12 .

To obtain $Z_{c}$ coordinate, which allows the generation of the $2 \mathrm{D}$ profile, this one is defined by equation 13 , which as observed, is composed by two expressions $13 \mathrm{a}$ and $13 \mathrm{~b}$

Equation 13 a corresponds to the equation of the circle, which is used to calculate $Z_{c}$ when " $X$ " is bigger then " $X_{n}$ " (equation 2), but smaller or equal to " $X_{c}$ " (equation 12).

Equation $13 \mathrm{~b}$ corresponds to the equation of a line, which is used to calculate " $Z_{c}$ " when " $X$ " is bigger then " $X_{c}$ " (equation 12) but smaller than " $X_{n+1}$ " (equation 4). It must be highlighted that these equations were obtained by using the MathCad software version 14.

$$
X_{c}=\frac{-\left[m\left(Z_{b}-Z_{n}\right)-X_{n}\right]+\sqrt{\left[m\left(X_{b}-Z_{n}\right)-X_{n}\right]^{2}-\left(m^{2}+1\right) \cdot\left[\left(Z_{b}-Z_{n}\right)^{2}+X_{n}{ }^{2}-r^{2}\right]}}{\left(m^{2}+1\right)}
$$

$$
\begin{array}{l|ll}
r+\varepsilon_{a_{i}}-\sqrt{r^{2}-\left[X-\left(n f_{z}+\varepsilon_{r_{i}}\right)\right]^{2}} & \forall n \wedge n f_{z}+\varepsilon_{r_{i}} \leq X \leq X_{c} \\
(13) & -\tan \left(K_{i+1}\right) \cdot\left(X-\left((n+1) f_{z}+\varepsilon_{r_{i+1}}\right)\right)+\varepsilon_{a_{i+1}} & \\
& & \forall n \wedge X_{c}<X \leq(n+1) f_{z}+\varepsilon_{r_{i+1}}
\end{array}
$$

It must be highlighted that the developed model is valid for the average surface roughness down to the center of the facing pass, where the center is defined by the path that the axis of rotation of the tool takes across the surface. 


\section{Experimental procedure for the validation of the developed geometrical model for surface roughness prediction}

Once the model was developed, this was validated by comparing the predicted values of surface roughness obtained from the model with experimental values obtained when face milling aluminium alloy 7075-T7351 samples with the following dimensions, $333.3 \times 76.2 \times 31.75 \mathrm{~mm}$.

The selection of this material was based on its importance in the aerospace industry due to its high toughness characteristic, been widely used where low weight is needed such as in plates, sheets and extrusions of airframes. The selection of square inserts is to improve prediction methods to estimate surface roughness on face milling parts when using this insert geometry and in addition, square inserts also allow shoulder cuts.

Table 1 and Table 2 show the chemical composition and the mechanical properties of this Al 7075-T7351 respectively.

Table 1- Chemical composition of Al 7075-7351

\begin{tabular}{ccccc}
\hline $\boldsymbol{\% A l} \pm \mathbf{0 . 1}$ & \% Cr $\pm \mathbf{0 . 0 0 7}$ & \% Cu $\pm \mathbf{0 . 0 1 3}$ & $\mathbf{\% M g} \pm \mathbf{0 . 3 8 1}$ & $\boldsymbol{\% Z n} \pm \mathbf{0 . 0 2 0}$ \\
\hline 87.1 & 0.174 & 1.586 & 2.693 & 5.240 \\
\hline Varian Spectrophotometer. Model AA-275. (weight percentage) & &
\end{tabular}

Table 2- Mechanical properties of Al7075-T7351

\begin{tabular}{cc}
\hline$S_{u}(\mathrm{MPa})$ & 593 \\
\hline$S_{y}(\mathrm{MPa})$ & 448 \\
\hline $\mathrm{HBN}^{*}$ & 135 \\
\hline Load $500 \mathrm{Kg}$ and $\emptyset_{\text {ball }}=10 \mathrm{~mm}$ &
\end{tabular}

As a cutting tool standard insert holder of $\emptyset_{\text {Tool }}=32 \mathrm{~mm}$, with two (2) teeth was used. Two types of uncoated indexable inserts, SDHT 120508FR-ALP CWK26 and SDHT 120525FR-ALP CWK26 were used for the experiments where the first one corresponds to $0.8 \mathrm{~mm}$ of tool nose radius and the second to $2.5 \mathrm{~mm}$ of tool nose radius. This type of insert was recommended by the tool supplier for the machining of aluminium alloy under a wet cutting operation. Figure 4 shows a scheme of the insert geometry used for this study. 

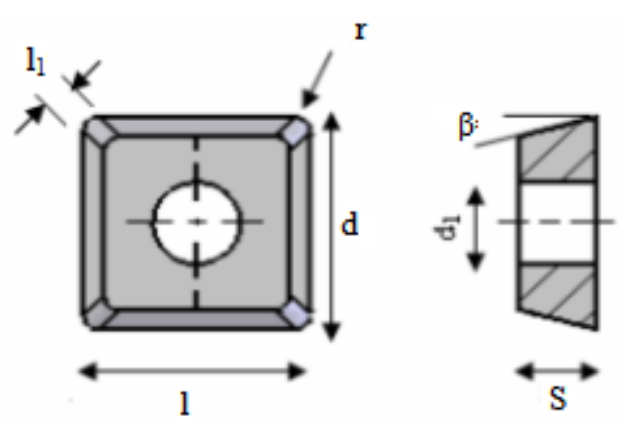

$\mathrm{d}=12.7 \quad \mathrm{l}=12.7 \quad \mathrm{~S}=5.0 \quad \mathrm{l}_{1}=2.2 \quad \mathrm{r}=0.8 / 2.5 \quad \beta=15^{\circ}$

Figure 4- Geometry and dimension of the tip used for the experiments. Units in mm.

As suggested by Diniz and Filho [18], in order to achieve a better performance of the tool (longer tool life) by removing the material in just one single pass the following conditions must be applied: 1) $\emptyset_{\mathrm{TOOL}}>$ workpiece width; in our case, $32 \mathrm{~mm}>31.75 \mathrm{~mm}$ and 2) a symmetric position of the tool against the workpiece. Figure 5 shows a schematic of the cutting process.

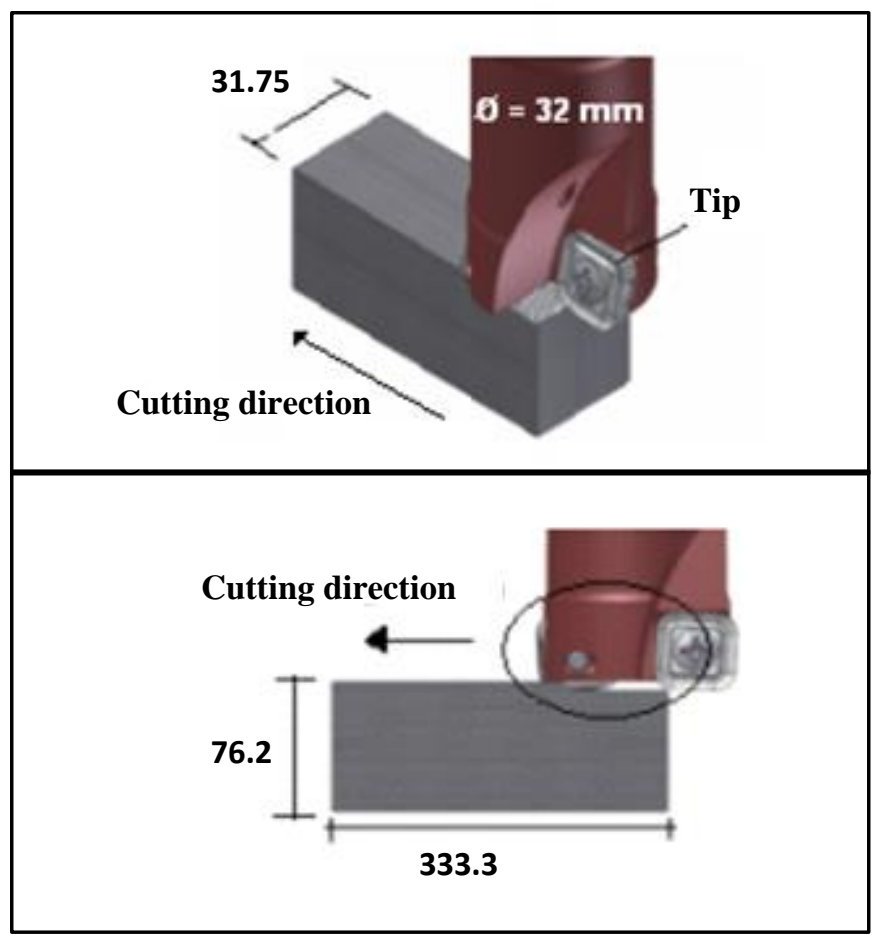

Figure 5- Scheme of the cutting process used in this study. 
The cutting parameters selected for this study were the cutting speed, the feed per tooth, the axial depth of cut and the tool nose radius, since from previous research it was observed that these variables had the highest influence on the surface roughness of the workpiece. [20-22]. Table 3 shows the values of the selected cutting parameters.

Table 3- Selected cutting parameters for the study.

\begin{tabular}{|c|c|c|c|c|}
\hline d্ঠ & $>\widehat{\overparen{\Xi}}$ & N & $\sigma^{2} \widehat{\underline{\mathrm{E}}}$ & $-\widehat{\mathrm{E}}$ \\
\hline 1 & 600 & 0.1 & 3.0 & 0.8 \\
\hline 2 & 800 & 0.2 & 3.5 & 2.5 \\
\hline 3 & 1000 & 0.3 & 4.0 & - \\
\hline 4 & 1200 & - & - & - \\
\hline 5 & 1400 & - & - & - \\
\hline 6 & 1600 & - & - & - \\
\hline
\end{tabular}

As observed from Table 3, six (6) levels were selected for the cutting speed, three (3) levels for the feed per tooth and axial depth of cut and two (2) levels for the tool nose radius parameter.

A Deckel Maho, DMV 50 evolution, CNC, High speed vertical machine centre, with a maximum spindle speed of $18000 \mathrm{rpm}$ was used for the face milling operation. All the tests were conducted under Minimum Quantity of Lubricant (MQL), since: 1) tool wear was not considered as a criterion that will affect the result of the cutting process due to the small amount of material that was removed from the workpiece, (one single pass of $333.3 \mathrm{~mm}$ ) 2) new inserts were used for each trial and 3) this material needed to be cut under a MQL cutting condition.

For the Design of Experiment (DoE), the Taguchi method was applied. This method uses a special design of orthogonal array $(\mathrm{OA})$ to study the entire parameters space with only a few numbers of experiments. The selection of the appropriate $\mathrm{OA}$ is based on the following criteria: the numbers of factors and interaction of interest, the numbers of levels for the factors of interest and the desired experimental resolution or cost limitation [23]. In this study a $\mathrm{L}_{36}$ mixed level design $\left(\mathrm{L}_{36}=6^{1} \cdot 3^{2} \cdot 2^{1}\right)$ was selected. Table 4 show the orthogonal array selected for the study, where numbers 1 to 6 represent the levels of each cutting variable. 
Table 4- $\mathrm{L}_{36}$ orthogonal array selected for Al 7075-T7351 studies

\begin{tabular}{|c|c|c|c|c|}
\hline Trial & $V$ & $f \mathbf{z}$ & $a_{p}$ & $r$ \\
\hline 1 & 1 & 1 & 1 & 1 \\
\hline 2 & 1 & 2 & 2 & 1 \\
\hline 3 & 1 & 3 & 3 & 1 \\
\hline 4 & 2 & 1 & 2 & 1 \\
\hline 5 & 2 & 2 & 3 & 1 \\
\hline 6 & 2 & 3 & 1 & 1 \\
\hline 7 & 3 & 1 & 3 & 1 \\
\hline 8 & 3 & 2 & 1 & 1 \\
\hline 9 & 3 & 3 & 2 & 1 \\
\hline 10 & 1 & 1 & 1 & 2 \\
\hline 11 & 1 & 2 & 2 & 2 \\
\hline 12 & 1 & 3 & 3 & 2 \\
\hline 13 & 2 & 1 & 2 & 2 \\
\hline 14 & 2 & 2 & 3 & 2 \\
\hline 15 & 2 & 3 & 1 & 2 \\
\hline 16 & 3 & 1 & 3 & 2 \\
\hline 17 & 3 & 2 & 1 & 2 \\
\hline 18 & 3 & 3 & 2 & 2 \\
\hline 19 & 4 & 1 & 1 & 1 \\
\hline 20 & 4 & 2 & 2 & 1 \\
\hline 21 & 4 & 3 & 3 & 1 \\
\hline 22 & 5 & 1 & 2 & 1 \\
\hline 23 & 5 & 2 & 3 & 1 \\
\hline 24 & 5 & 3 & 1 & 1 \\
\hline 25 & 6 & 1 & 3 & 1 \\
\hline 26 & 6 & 2 & 1 & 1 \\
\hline 27 & 6 & 3 & 2 & 1 \\
\hline 28 & 4 & 1 & 1 & 2 \\
\hline 29 & 4 & 2 & 2 & 2 \\
\hline 30 & 4 & 3 & 3 & 2 \\
\hline 31 & 5 & 1 & 2 & 2 \\
\hline 32 & 5 & 2 & 3 & 2 \\
\hline 33 & 5 & 3 & 1 & 2 \\
\hline 34 & 6 & 1 & 3 & 2 \\
\hline 35 & 6 & 2 & 1 & 2 \\
\hline 36 & 6 & 3 & 2 & 2 \\
\hline
\end{tabular}

Once the specimens were machined they were put on a bench for surface roughness measurement. The surface roughness was measured across the direction of the machined surface lay (feed direction) using a noncontact white lamp profilometer ProScan 2000 and following ASME B46.1 standards.

The roughness average value of each specimen was determined by measuring three areas (line roughness average measurement), located in the centre of the specimen, specifically, $8 \mathrm{~cm}$ away from the edge of the workpiece and just where the vice was retaining the workpiece. The idea of measuring the roughness at the workpiece centre, was in order to make sure that the obtained values of surface roughness were not affected by possible vibrations due to the impact of the tool entering the workpiece. Then an average of these three values was used to represent the experimental surface roughness value of the specimen $\left(R_{a}\right)$. The surface roughness values measured within the measuring area are sufficient to represent the roughness of each workpiece [24]. 
In this case study, the sample size for the $R_{a}$ measurement was $4 \mathrm{~mm}$ in the $X$ direction and $4 \mathrm{~mm}$ in the $Y$ direction. In order to cover this $4 \times 4 \mathrm{~mm}^{2}$ area, a total of 1335 steps with a size of $0.003 \mathrm{~mm}$ and a $0.8 \mathrm{~mm}$ for cut-off wavelength.. Once measuring the roughness after these conditions, the waviness filter was applied and the final roughness of value $\left(R_{a}\right)$ was reported. The selection of a proper value of cut-off wavelength is important as this factor determines which wavelength belongs to waviness and which belongs to roughness. The value selected for the measurements was suggested by the manufacturer's user's guide profilometer ProScan 2000. Besides the three values of surface roughness obtained from the machined surface by using the ProScan 2000, the 2D surface roughness profile was also obtained.

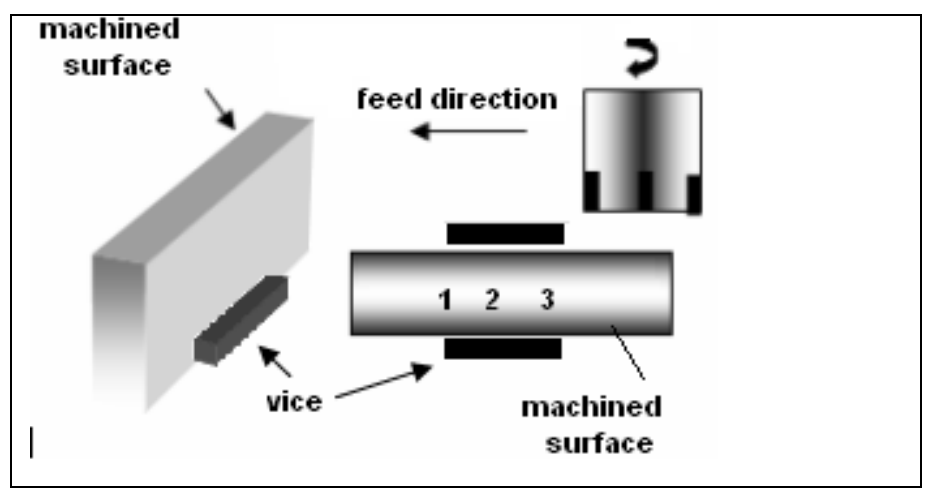

Figure 6- Scheme indicating the areas where the surface roughness measurements were taken

Table 5- Experimental and predicted values of surface roughness, radial $\varepsilon_{r}$ and axial $\varepsilon_{a}$ deviations, angle $K_{i}$ and $\%$ RE.

\begin{tabular}{|c|c|c|c|c|c|c|}
\hline Trial & $K_{i}\left({ }^{\circ}\right)$ & $\varepsilon_{r}(\mathbf{m m})$ & $\varepsilon_{a}(\mathbf{m m})$ & $\begin{array}{c}R_{a} \\
\pm 0.001(\mu \mathrm{m})\end{array}$ & $\begin{array}{c}R_{a_{p}} \\
\pm 0.001(\mu \mathrm{m})\end{array}$ & $\% \boldsymbol{R E}$ \\
\hline 1 & 0.40 & 0.009 & 0.0002 & 0.699 & 0.686 & 1.9 \\
\hline 2 & 0.29 & 0.001 & 0.0002 & 1.017 & 1.014 & 0.3 \\
\hline 3 & 0.28 & 0.009 & 0.0002 & 1.472 & 1.473 & 0.1 \\
\hline 4 & 0.39 & 0.002 & 0.0002 & 0.679 & 0.671 & 1.2 \\
\hline 5 & 0.24 & -0.009 & 0.0002 & 0.838 & 0.846 & 1.0 \\
\hline 6 & 0.12 & -0.008 & 0.0001 & 0.646 & 0.644 & 0.3 \\
\hline 7 & 0.41 & -0.008 & 0.0003 & 0.712 & 0.716 & 0.6 \\
\hline 8 & 0.24 & -0.009 & 0.0002 & 0.835 & 0.846 & 1.3 \\
\hline 9 & 0.13 & -0.006 & 0.0001 & 0.699 & 0.692 & 1.0 \\
\hline 10 & 0.22 & -0.009 & 0.0002 & 0.376 & 0.382 & 1.6 \\
\hline 11 & 0.11 & 0.001 & 0.0001 & 0.399 & 0.400 & 0.3 \\
\hline 12 & 0.11 & 0.008 & 0.0001 & 0.596 & 0.587 & 1.5 \\
\hline 13 & 0.19 & 0.008 & 0.0001 & 0.328 & 0.361 & 10.1 \\
\hline 14 & 0.11 & -0.008 & 0.0001 & 0.368 & 0.384 & 4.3 \\
\hline 15 & 0.08 & -0.007 & 0.0001 & 0.425 & 0.443 & 4.2 \\
\hline 16 & 0.21 & -0.009 & 0.0002 & 0.365 & 0.375 & 2.7 \\
\hline 17 & 0.12 & -0.002 & 0.0001 & 0.422 & 0.419 & 0.7 \\
\hline 18 & 0.07 & -0.009 & 0.0001 & 0.381 & 0.401 & 5.2 \\
\hline
\end{tabular}




\begin{tabular}{lllllll}
\hline 19 & 0.31 & -0.008 & 0.0002 & 0.548 & 0.539 & 1.6 \\
\hline 20 & 0.22 & 0.008 & 0.0001 & 0.759 & 0.764 & 0.7 \\
\hline 21 & 0.15 & 0.001 & 0.0001 & 0.781 & 0.795 & 1.8 \\
\hline 22 & 0.39 & 0.005 & 0.0002 & 0.688 & 0.689 & 0.1 \\
\hline 23 & 0.19 & 0.002 & 0.0001 & 0.668 & 0.662 & 0.9 \\
\hline 24 & 0.13 & -0.009 & 0.0001 & 0.694 & 0.685 & 1.3 \\
\hline 25 & 0.26 & 0.009 & 0.0001 & 0.461 & 0.470 & 2.0 \\
\hline 26 & 0.25 & -0.007 & 0.0002 & 0.872 & 0.879 & 0.8 \\
\hline 27 & 0.17 & 0.005 & 0.0001 & 0.888 & 0.893 & 0.6 \\
\hline 28 & 0.21 & -0.008 & 0.0002 & 0.365 & 0.378 & 3.6 \\
\hline 29 & 0.13 & 0.005 & 0.0001 & 0.461 & 0.457 & 0.9 \\
\hline 30 & 0.08 & -0.008 & 0.0001 & 0.415 & 0.442 & 6.5 \\
\hline 31 & 0.20 & 0.009 & 0.0001 & 0.344 & 0.337 & 2.0 \\
\hline 32 & 0.13 & 0.002 & 0.0001 & 0.437 & 0.451 & 3.2 \\
\hline 33 & 0.08 & -0.009 & 0.0001 & 0.408 & 0.441 & 8.1 \\
\hline 34 & 0.23 & -0.006 & 0.0002 & 0.408 & 0.398 & 2.5 \\
\hline 35 & 0.12 & -0.008 & 0.0001 & 0.418 & 0.408 & 2.4 \\
\hline 36 & 0.09 & -0.005 & 0.0001 & 0.453 & 0.486 & 7.3 \\
\hline & & & & & $\% \boldsymbol{E}^{*}$ & 2.4
\end{tabular}

The relative error between the experimental value and the predicted value was calculated using equation 14.

$$
\% R E=\left|\frac{R_{a}-R_{a_{p}}}{R_{a}}\right| \cdot 100
$$

Where:

$\% R E$ : Relative error

$R_{a}: \quad$ Experimental surface roughness $(\mu \mathrm{m})$

$R_{a_{p}}: \quad$ Predicted surface roughness $(\mu \mathrm{m})$

As previously stated (Figure 2) the axial deviation is the one that influences the deepness of the surface roughness profile. When analyzing Table 6 the behaviour of the axial deviation is presented. As observed as the value of this variable is increased higher than $0.0005 \mathrm{~mm}$, the thick dash line which corresponds to tooth $(i+1)$ does not make any contributions on the development of the surface roughness profile, this is why the axial deviation is a very small value. The deviations (tool run outs) were obtained by using arbitrary numbers and in this case a radial deviation of $\varepsilon_{r} \leq 0.009 \mathrm{~mm}$ and axial deviation of $\varepsilon_{a} \leq 0.0003 \mathrm{~mm}$ (this deviation affects the deepness of the roughness profile and as previously mentioned and as observed in Table 6 deviation needs to be less than $0.0005 \mathrm{~mm}$ in order to contribute to the profile). 
Table 6- Example of 2D theoretical surface roughness profile when considering different values of axial deviation.

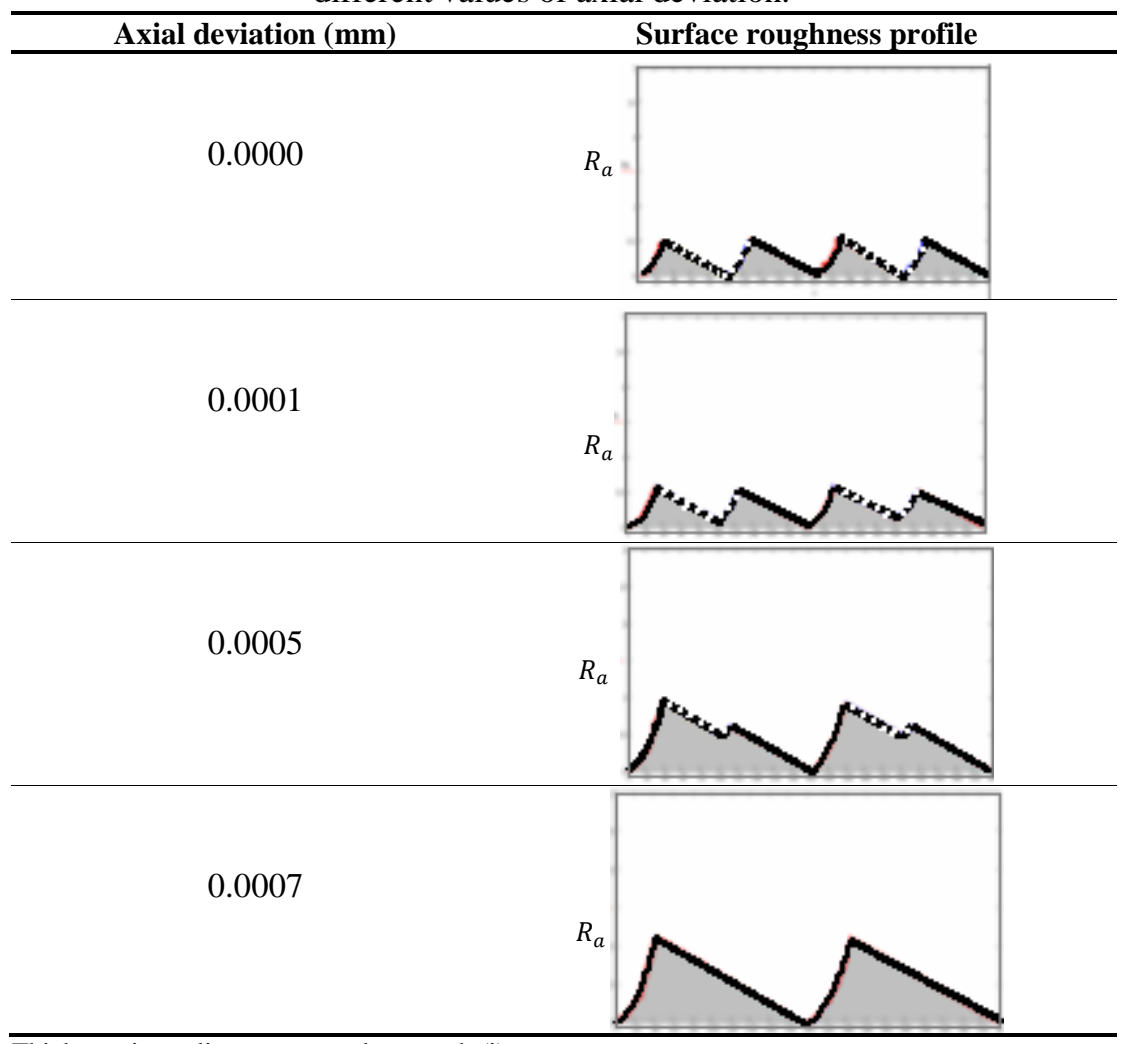

Thick continues line corresponds to tooth (i)

Thick dash line corresponds to tooth (i+1)

With regard to the value of angle $K_{i}$, these were obtained from previous analysis of a surface roughness profile where $\tan \left(K_{i}\right)=\frac{R_{a}}{f_{z}}$ was considered. Also when analyzing this variable it was observed a similar value of angle $K_{i}$ for the same group of feed per tooth and tool nose radius.

From Table 5 it can be observed that the $\% R E^{*}$ (Relative Error Percentage average) is 2.4. This result is considered as an excellent approach, since the developed model is able to predict the surface roughness with almost $98 \%$ of accuracy when comparing it with the experimental values of surface roughness obtained when face milling the Al 7075-T7351. Despite the fact that few \%RE gave values higher than 2.4\% (10\%), it must be highlighted that in general a difference of $20 \%$ between the three values of surface roughness measurements conducted in each machined surface was obtained, for this reason the approach of the developed model is considered as excellent. A visual representation of the results shown in Table 5 is presented in Figure 7 where as it was expected, an overlap between the predicted and experimental values of surface roughness is observed due to the small value of $\% R E$ that was achieved by the developed model. 


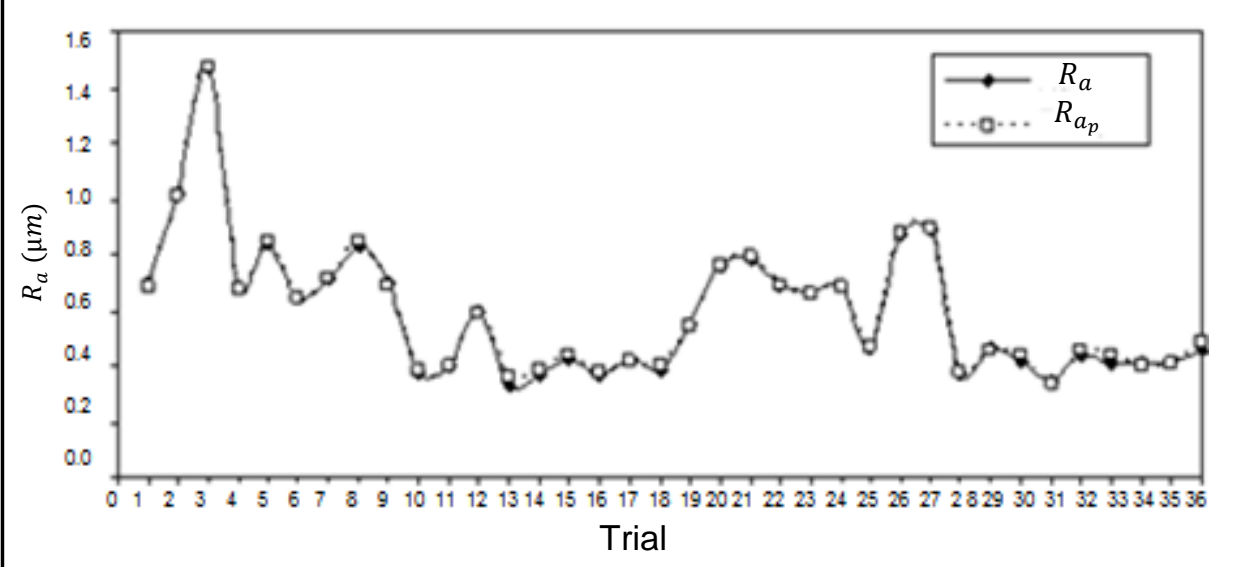

Figure 7-Experimental and predicted values of surface roughness for each conducted trial

As previously stated the developed model is capable of not only predicting the surface roughness but to reproduce the surface roughness profile. Figure 8 shows a comparison between a $2 \mathrm{D}$ geometrical profile obtained by using the developed model and the 2D experimental surface roughness profile for specific cutting conditions.

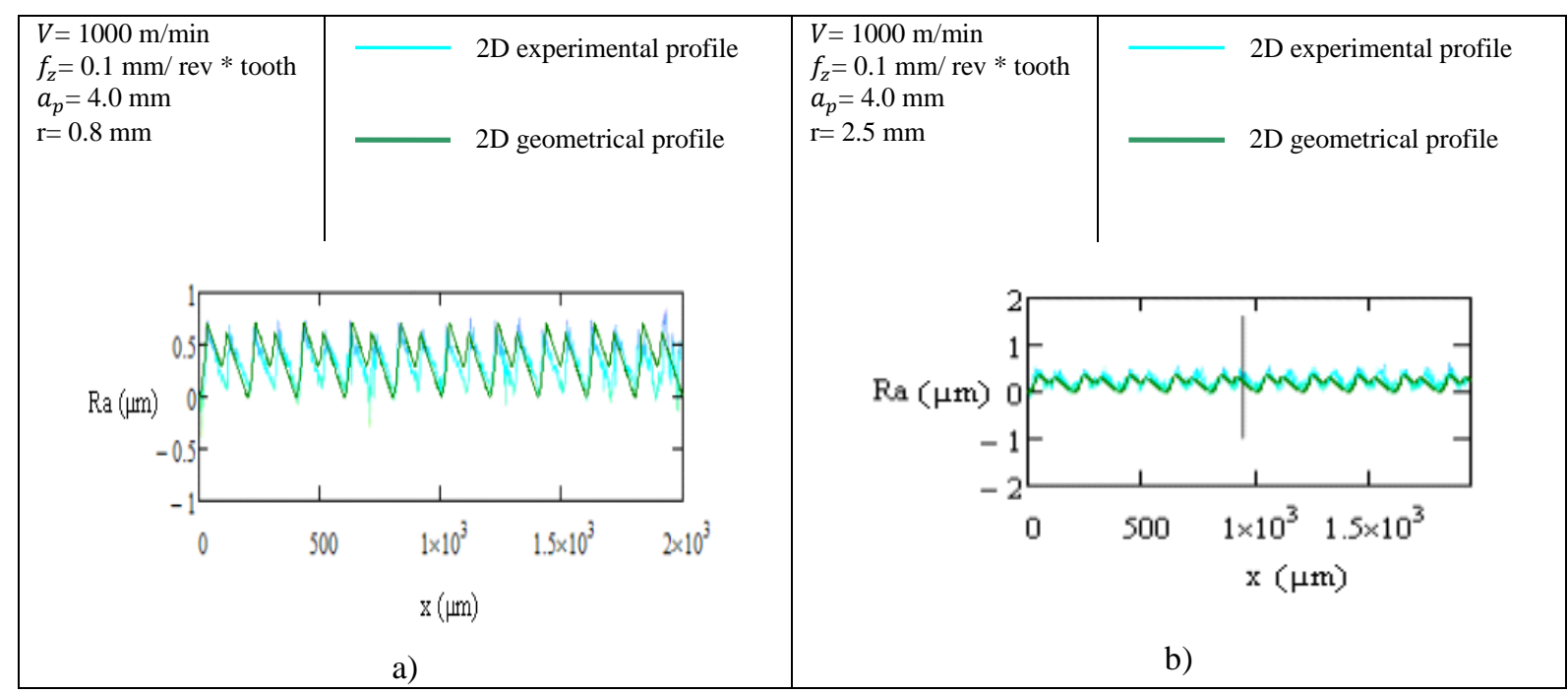

Figure 8- Comparison between the 2D profiles obtained by the developed geometrical model and the experimental profile. a) trial 7 and b) trial 16 
When analyzing Figure 8, it can be observed that a very good approximation between the predicted surface roughness profile and the experimental surface roughness profile, this is due to the high accuracy reached by the developed model. It must be highlighted that this behavior remained constant for all the 36 trials that were conducted in this study. Finally the results show that a unique cutter tooth can define the surface profile of milled parts when considering the front cutting process and these results are in agreement with the research of Franco [10].

\section{Conclusions}

In this research it has been demonstrated the useful of developing models for the prediction of the surface roughness as a fundamental variable in the surface integrity of mechanical components. The use of the models allows decreasing trial and errors experiments and the search of optimal variables for specific value of roughness. The developed model is simple to use, its accuracy is $98 \%$, and not only allows obtaining the value of roughness but also the development of the $2 \mathrm{D}$ surface roughness profile. The model can be applied to any combination of material workpiece and tool when tool wear is not considered. Also since the model is based on a geometrical analysis it can be applied to any tool diameter, number of teeth and square insert with any value of tool nose radius.

\section{Further work.}

Considering the importance and impact of the tool wear on the surface roughness, further work will be conducted in order to incorporate this value on the development of a new model for surface roughness prediction, where tool wear mechanism such as abrasion and adhesion will be considered.

\section{Acknowledgements}

The authors gratefully acknowledge partial support of this work to the University of Bath with the physical facilities needed to complete it.

\section{References}

[1] J-D Kim and Y-H Kang. "High Speed Machining of Aluminium Using Diamond End Mills". International Journal of Machining Tool and Manufacturing. Vol 37 (8). (1997), pp. 1155-1165.

[2] K Medicus; M Daves; B Dutterer; C Evans and R Fielder. "Tool Wear and Surface Finish in High Speed Milling of Aluminium Bronze". Machining Science and Technology. Vol 5(2), (2001), pp. 255-268.

[3] E.S Gadelmawla; M Koura. M; T.M.A Maksoud; I.M Elewa and H.H Soliman. "Roughness Parameters". Journal of Materials Processing Technology. Vol 123, (2002), pp.133-145.

[4] K Saï K and W Bouzid. "Roughness Modeling in Up Face Milling". International Journal of Advance Manufacturing Technology. Vol. 26, (2005) pp. 324-329. 
[5] M C Cakir; E Cihat, I Demirayak, "Mathematical Modeling of Surface Roughness for Evaluating the Effects of Cutting Parameters and Coating Material". Journal of materials Processing Technology. Vol 209. (2009), pp 102-109.

[6] T Childs; K Maekawa; T Obitawa and Y Yamane. "Metal Machining. Theory and Applications". John Wiley and Sons. First edition. UK, 2000

[7] S Kalpakjian. "Manufacturing Processes for Engineering Materials and Technology". Vol. 157-158. (2003) pp. 543-552.

[8] DBaek, T Kyun and H Kim. "Optimization of Feed rate in a Face Milling Operation Using a Surface Roughness Model”. International Journal of Machine Tools \& Manufacture, 41. (2001), pp. 451-462.

[9] Y Wang and H Chang. "Experimental Study of Surface Roughness in Slot End Milling Al 2014-T6.". International Journal of Machine Tools \& Manufacture, 44. (2004) pp. 51-57.

[10] P Franco; M Estrems and F Faura. "Influence of radial and Axial Runouts of Surface Roughness in face Milling with Round Inserts Cutting Tools". International Journal of Machine Tools \& Manufacture 44, (2004), pp. 1555-1565.

[11] H Oktema; T Erzurumlu and H Kurtaran. "Application of Response Surface Methodology in the Optimization of Cutting Conditions for Surface Roughness". Journal of Materials Processing Technology, 170 (2005), pp. 11-16.

[12] S Reddy and R Venkateswara. "Selection of Optimum Tool Geometry and Cutting Conditions Using a Surface Roughness Prediction Model for End Milling". International Journal of Advance Manufacturing Technology, 26, (2006), pp. 1202-1210.

[13] S Ryua; D Choib and N Chong. "Roughness and Texture Generation on End Milled Surfaces". International Journal of Machine Tools \& Manufacture 46, (2006), pp. 404-412.

[14] B Ozcelik and M Bayramoglu. "The Statistical Modeling of Surface Roughness in High-Speed Flat End Milling”. International Journal of Machine Tool \& Manufacture 46 (2006) , pp. 1395-1402.

[15] C Jesuthanam; S Kumanan and P Asojan. "Surface Roughness Prediction Hybrid Neural Network". Machining Science Technology, 111 (2007), pp. 271-286

[16] J Zhang; J Chenb and D Kirby. "Surface Roughness Optimization in an End Milling Operation Using the Taguchi Design Method”. Journal of Materials Processing Technology 184 (2007), pp. 233-239.

[17] S Bharathi Raja and N Baskar. "Application of Particle Swarm Optimization Technique for Achieveing Desired Milled Surface Roughness in Minimum Machining Time". Expert Systems with Applications 39, pp 5982-5989

[18] P.J. Arrazola, T Özel, D Umbrello, M Davies and I.S Jawahir. "Recent Advances in Modelling of Metal Machining Processes". CIRP Annals. Manufacturing Technology 62 (2013) pp 695-718

[19] A Diniz and J Filho. "Influence of the Relative Position of Tool and Workpiece on Tool Life, Tool Wear and Surface Finish in the Face Milling Process". Wear, Vol 232, (1999) pp 67-75.

[20] TS Lin. "Reliability and Failure of face Milling Tools When Cutting Stainless Steels". Journal of Materials Processing Technology . Vol. 79, (1998), pp. 41-46. 
[21] TS Lin. "Experimental Design and Performance Analysis of TiN-Coated Carbide Tool in Face Milling Stainless Steel". Journal of Materials Processing Technology. Vol 127, (2002) pp. 1-7

[22] J A Ghani; I A Choudhury and H Hassan. "Application of Taguchi Method in the Optimization of End Milling Parameter". Journal of Material Processing Technology. Vol. 145, (2004) pp. 84-92.

[23] D Montgomery. "Design, Analyses of Experiments”. Third edition. John Whiley and Sons. 1997

[24] Y Tsai; J Chenb and S Lous. “An In-Process Surface Recognition System Based on Neural Networks in End Milling Cutting Operations”. International Journal of Machine Tools \& Manufacture, 39,(1999) pp. 583605. 